\title{
BARREIRAS E FACILITADORES PARA A IMPLEMENTAÇÃO DO PROGRAMA SEGUNDO TEMPO: UM ESTUDO DE CASO ${ }^{1}$
}

\author{
Ana Paula Prestes de Souza \\ Universidade Federal do Paraná, Curitiba, Paraná, Brasil \\ Doralice Lange de Souza \\ Universidade Federal do Paraná, Curitiba, Paraná, Brasil \\ Suelen Barboza Eiras de Castro \\ Universidade Federal do Paraná, Curitiba, Paraná, Brasil
}

\begin{abstract}
Resumo
Investigamos as principais barreiras e facilitadores para a implementação do Programa Segundo Tempo (PST). A pesquisa foi qualitativa e os dados coletados através de entrevistas semiestruturadas. Para o coordenador do PST no município, as principais barreiras relacionam-se com a falta de articulação entre os interesses das partes envolvidas. Já para os coordenadores de núcleo, estão ligadas com a falta de autonomia e apoio para o trabalho. Os principais facilitadores são a oferta de materiais esportivos, carga horária para planejamento e reforço alimentar. Alguns fatores são vistos ora como barreiras e ora como facilitadores: estrutura física para as atividades e armazenamento de materiais e presença de outros programas nas proximidades onde o PST é desenvolvido.
\end{abstract}

Palavras-chave: Políticas Públicas. Esportes. Estudo de caso.

\section{Introdução}

Programa Segundo Tempo, criado em 2003, é uma iniciativa do Governo Federal, mais especificamente do Ministério do Esporte (ME). Este Programa tem como objetivo "promover o desenvolvimento integral de crianças, adolescentes e jovens como fator de formação da cidadania e melhoria da qualidade de vida" (BRASIL, 2011a, p. 9), por meio da democratização do acesso ao esporte educacional. Ele ocorre no período de contraturno escolar e tem como público alvo crianças e adolescentes entre 6 e 17 anos, prioritariamente alunos de escolas públicas e/ou em áreas de vulnerabilidade social (BRASIL, 2011a).

1-Pesquisa financiada pelo programa de apoio à Iniciação Científica $\mathrm{PIBIC/CNPq}$ e Ministério do Esporte (Rede CEDES). 
A execução do Programa ocorre através de convênios com entidades públicas e privadas sem fins lucrativos. Estes visam a implantação de núcleos do Programa, chamados de "Núcleos de Esporte Educacional" (NEE). Cada NEE deve ser composto por 100 crianças, adolescentes e jovens e deve ofertar atividades esportivas a serem orientadas e desenvolvidas por um monitor e um coordenador de núcleo ${ }^{2}$ da área de Educação Física ou Esporte. As atividades podem ocorrer tanto no ambiente escolar como em espaços comunitários (públicos ou privados). Cada NEE deve receber um kit de materiais esportivos, além de uniforme (camiseta e bermuda) e reforço alimentar para todos os beneficiados, sendo que os primeiros ficam a cargo do ME, e este último a cargo da instituição que pactua o convênio (BRASIL, 2011a).

O PST atende hoje aproximadamente 2,2 milhões de crianças e adolescentes em 792 municípios brasileiros (BRASIL, 2011b). No período de 2003 a 2006 ele foi considerado como a principal ação do ME (ATHAYDE; MASCARENHAS, 2011) e tem sido considerado "o maior programa de inclusão social e acesso ao esporte educacional do país" (BRASIL, 2010, p. 11).

A partir de uma revisão prévia da literatura verificamos que a produção científica sobre o PST é escassa. Alguns trabalhos fazem relatos de experiência do Programa (ATHAYDE; MASCARENHAS, 2009; LORENZINI; SANTOS, 2009; MENDES et al., 2007; NUNES JUNIOR; AMARAL, 2008; SILVA; ROCHA, 2007; SOUSA NETO; RODRIGUES, 2007; TERRA; MASCARENHAS, 2010). Já outros enfatizam questões relativas à políticas públicas e modelos de gestão do PST (ATHAYDE, 2009; ATHAYDE; MASCARENHAS, 2011). Ainda outros realizam uma avaliação do Programa (MOREIRA et al., 2007; SOUSA et al., 2010). Tendo em vista a relevância do PST e a necessidade de mais produção na área, desenvolvemos esta pesquisa tendo como objetivo identificar os principais facilitadores e barreiras (o que favorece e o que dificulta) para a implementação do Programa Segundo Tempo em um município da região sul do Brasil. Visamos gerar subsídios para a melhoria do Programa no município estudado, bem como em outros municípios que enfrentam realidade similar.

2-O coordenador de núcleo tem a função de planejar, desenvolver, acompanhar, supervisionar e avaliar as atividades de um núcleo em específico (BRASIL, 2011a). 


\section{Metodologia}

A pesquisa foi qualitativa e de cunho exploratório e os dados coletados através de entrevistas semiestruturadas. A coleta dos dados foi realizada de novembro a maio de 2012 em um município da região sul do Brasil. Foram entrevistados sete coordenadores de núcleo $(\mathrm{CN})$ e um dos três coordenadores do Programa (CP) no município ${ }^{3}$. As entrevistas ocorreram individualmente e tiveram uma duração média de uma hora e trinta minutos. Elas exploraram, entre outras questões, o perfil do entrevistado, características dos participantes e do PST no município, os principais facilitadores e barreiras para a implementação do Programa e sugestões para a melhoria do mesmo. Todas as entrevistas foram gravadas e transcritas na íntegra. Para proteger a identidade do convênio estudado e dos sujeitos entrevistados, utilizaremos apenas nomes fictícios femininos.

A análise dos dados foi realizada com base na teoria fundamentada (GLASER; STRAUSS, 1967). Cada entrevista foi analisada individualmente e a partir daí retirados os principais temas que emergiram da fala de cada um dos entrevistados. Num segundo momento cruzamos os temas que surgiram dos diferentes entrevistados e os organizamos em categorias.

\section{Resultados e discussão}

Dividimos os resultados e discussão em três sub-tópicos: "barreiras", "facilitadores" e "ora barreiras, ora facilitadores". Denominamos este último tópico desta forma por haverem temas que, ao mesmo tempo em que apareceram como facilitadores para alguns entrevistados, apareceram como barreiras para outros, e vice-versa.

\section{Barreiras}

A principal barreira para a implementação do PST no município estudado, de acordo com a coordenadora do Programa entrevistada, é

3-Conforme diretrizes do PST (BRASIL, 2011a), cada convênio deve ter um coordenador geral, um coordenador pedagógico e um coordenador setorial os quais têm como função nortear o trabalho dos núcleos. Adotamos a expressão "coordenadora do Programa", sem denominar qual entrevistamos, para resguardar a sua identidade. 
a incompatibilidade entre os interesses dos gestores do município e as complexidades envolvidas na proposta do Programa e nos processos de implementação do mesmo.

A pessoa que está ali fazendo a gestão do Programa ele visualiza o quê? Atendimento, vamos atender as [...] trinta e sete comunidades que precisam, que são carentes [...]. Mas e daí, e depois, como que a gente vai fazer? Isso eles não conseguem visualizar [...]. No meu modo de ver a falha está nesse pensamento dessa gestão que, muitas vezes, está vinculado com uma questão política [...] no sentido de votos mesmo e ações que precisam ser realizadas no município. Mas a maneira como isso vai ser feito não interessa muito, né? (Bárbara, $\mathrm{CP}$ )

Em algumas situações, como a citada acima, os programas governamentais, como o PST, são utilizados como mecanismos de propaganda eleitoral (ATHAYDE; MASCARENHAS, 2009; SOUSA NETO; RODRIGUES, 2007). Athayde (2009), por exemplo, aponta que no Distrito Federal (DF) muitos convênios foram realizados por meio de influências políticas, ignorando os critérios de demandas sociais previstos nas diretrizes do PST.

A principal dificuldade apontada pelas coordenadoras de núcleo é a falta de alguns materiais para a divulgação do Programa e para o desenvolvimento das aulas.

Eles [a coordenação geral] não me deram suporte pra isso. Então 300 convites eu tive que imprimir do meu bolso [...]. Eu trago de casa as coisas, bexiga, trago de casa, do meu bolso. [...] Esse armário [...] cola, giz, caneta, tudo de casa, oh, grampeador, tudo isso daqui a gente precisa, oh, até isso daqui, impressão da chamada. (Priscila, CN)

A falta de materiais tais como os citados acima também foi observada como uma barreira em um outro estudo sobre o PST (LORENZINI; SANTOS, 2009). Por outro lado, em alguns casos, tal como na cidade do Rio Grande-RS (MOREIRA et al., 2007), as próprias entidades que pactuaram o convênio disponibilizam este tipo de materiais.

Segundo a coordenadora do Programa, o ME e o município não garantem a compra de materiais didáticos e esportivos além dos que 
constam no kit esportivo. Desta forma, as coordenadoras de núcleo precisam improvisar pedindo ajuda para outras instituições.

O que a gente passava pra eles é que eles teriam que tentar negociar isso [...] com a escola, ou se estava numa estrutura da associação de bairro tentava ir com o presidente da associação, o que é muito difícil, né? Não vou te dizer que é fácil, a diretora vai falar, "não, opa, o estado não prevê pra mim dar isso pra você, daí se eu tiro daqui eu vou ficar sem, e aí?" E aí a gente comentava pra eles trazerem pra nós, pra ver o que a gente poderia solucionar via Secretaria de Esportes, algumas coisas a gente conseguia, outras não. (Bárbara, CP)

Outra dificuldade do PST mencionada pela coordenadora que entrevistamos é a falta de mais coordenadores para desenvolver o Programa no município e apoiar o trabalho dos coordenadores de núcleo. Ao todo são três coordenadores para trinta e sete núcleos. Esta realidade impossibilita os mesmos de cumprirem o seu papel conforme determinado pelas diretrizes do Programa.

Era muito cruel porque a gente estava em [...] três pessoas pra dar conta de trinta e sete núcleos, não tem condições. [...] Também há uma certa burocratização das ações, e isso atrapalhava muito, né? [...] As tarefas, as funções ficavam muito sobrecarregadas. (Bárbara, CP)

As exigências e os excessos de demandas burocráticas nas ações administravas do PST também são apontados como barreiras em outros estudos (ATHAYDE, 2009; ATHAYDE; MASCARENHAS, 2009). Estes fatores inclusive se constituíram em problemas que comprometeram a manutenção das parcerias e a continuidade do Programa no DF.

Uma das consequências da falta de um acompanhamento do trabalho dos núcleos é que o Programa fica nas mãos dos coordenadores de núcleo, que nem sempre cumprem com as suas obrigações.

Como a gente não tinha condições de acompanhar todos, ficava muito na autonomia de cada coordenador, e não eram todos que cumpriam o seu horário de trabalho, as suas funções, as suas 
metas. [...] Então a gente ficava muito nesse plano do discurso, né? "Oh, façam uma ação assim, façam uma ação assado". Mas definitivamente na prática isso não acontecia, né? (Bárbara, $\mathrm{CP}$ )

Enquanto a coordenadora do Programa no município reclama da sobrecarga de trabalho e consequente impossibilidade de acompanhar de perto todos os núcleos, as coordenadoras de núcleo percebem a falta de acompanhamento como displicência da coordenação geral.

Eu não sinto que estão preocupados com o que realmente eu estou fazendo [...]. [É] ausência. Acho que um exemplo disso é assim, nunca perguntarem como estão as aulas, [...] o que eu tô trabalhando. [...] Nunca ninguém perguntou, nem da direção da escola, nem da coordenação geral. (Flávia, CN)

Outra barreira levantada pelos entrevistados diz respeito à formatação do Programa. Ao mesmo tempo em que as suas diretrizes permitem que os convênios tenham autonomia para se adaptar às realidades locais onde são implementados, existem critérios e padrões a serem seguidos que dificultam tal adaptação e a implementação dos mesmos.

Ele vem todo formatado numa lógica [...] que não é muito maleável, você tem que entrar nessa lógica [...]. E aí entra numa estrutura de uma secretaria municipal, que as vezes não tem um suporte todo para absorver todas as exigências do Governo Federal. (Bárbara, CP)

O Projeto Pedagógico de Núcleo, ele é muito amarrado sabe? A gente tem que fazer assim de acordo com o modelo que o Ministério do Esporte lança [...] e muitas vezes o que eles falam não acontece, pode acontecer em um núcleo, mas não acontece no outro. [...] Eles falam uma coisa no papel, mas na prática acontece de outra forma. (Daniela, $\mathrm{CN}$ )

Enquanto os critérios e padrões estabelecidos pelas diretrizes do Programa servem para manter um mínimo de qualidade, eles comprometem a adequação do mesmo às diferentes realidades regionais (ATHAYDE; MASCARENHAS, 2009). 
Ainda outra dificuldade do Programa, segundo as coordenadoras de núcleo inseridas em escolas, é que elas precisam se adequar às exigências destas instituições.

Elas [diretora e vice-diretora] queriam que só os alunos realmente matriculados na escola participassem do Programa pra não ter pessoas diferentes [...] A direção também selecionou as crianças [...] de acordo com comportamento, falou assim "ah, essa criança aqui não vai dar certo, não merece [...]". Eu sinto que eu não tenho completa autonomia [...] Eu sempre tenho que estar abaixo da direção, acatando as regras e normas que elas estabelecem. (Flávia, CN)

Ao se atender às exigências da escola, tais coordenadoras se sentiram obrigadas a violar as diretrizes do Programa. No caso acima, por exemplo, a escola definiu os critérios de aceitação de alunos de acordo com o comportamento dos mesmos, e não de acordo com critérios sociais requeridos pelo PST. Esta realidade também foi verificada por Moreira et al. (2007).

Ainda outra barreira para a implementação do Programa, segundo as coordenadoras de núcleo, é que existe uma pressão muito grande para que cada núcleo atenda 100 crianças. Do contrário o núcleo pode fechar. Dos sete núcleos pesquisados, apenas um conseguiu atingiu esta meta. A maioria deles não possui condições de atender esta demanda.

Existem críticas, por parte de alguns autores, quanto à exigência do ME e outras entidades com o número de crianças que devem ser inscritas no Programa, a despeito de questões mais importantes tais como a qualidade do trabalho desenvolvido e o impacto do Programa na vida das crianças (ATHAYDE, 2009; NUNES JUNIOR; AMARAL, 2008). Vários fatores interferem para com a participação de um número maior de crianças no PST. Um deles é a concorrência com aulas de reforço escolar e com outros projetos sendo desenvolvidos no mesmo local ou nas escolas próximas ao núcleo no qual o PST está inserido. Em alguns núcleos esses projetos/atividades extracurriculares ocorrem nos mesmos dias e horários do PST.

A gente tem mais de 100 matriculadas ali [na escola], de manhã, $[. .$.$] só que também a gente tem o problema de que muitas$ 
crianças não podem participar do Programa porque [...] estão no reforço. Reforço é geralmente duas vezes por semana e pega os dias do Programa. (Flávia, CN)

Conforme apontam Terra e Mascarenhas (2010), o PST muitas vezes é implantado em comunidades de forma a se sobrepor a outros programas já existentes, o que demonstra certa desorganização quanto aos critérios de implantação do mesmo. Mas ao mesmo tempo que a existência de outros programas pode atrapalhar a participação de crianças no PST, eles podem também auxiliar. Se as atividades ofertadas não coincidirem em termos de dias e horários, parcerias podem ser estabelecidas.

Eu não tive que ir atrás [de crianças] [...] os que hoje estão inscritos, eles já estavam aqui quando eu cheguei [...] eles estavam já participando de atividades como [...] Projeto [...] [Y] desde o começo do ano. (Luciane, $\mathrm{CN}$ )

Dois fatores que limitam a participação de crianças no PST, quando o mesmo ocorre no espaço escolar, são as condições impostas pela escola em relação a quem pode, ou não, participar do Programa, e a disponibilidade de espaço para a realização das atividades.

A primeira grande barreira assim foi com a direção da escola assim, que eles não aceitavam, né, crianças de fora da escola. Sendo que outros núcleos têm crianças de todos [...] os lugares, e isso também diminuiu o número de crianças que estão [...] hoje no Programa. (Flávia, CN)

Eu nem consigo atender as 100 crianças que são previstas hoje [...] porque a escola é pequenininha [...] tem 200 crianças na escola no horário formal, curricular, 200, mais 100? [...] Não dá, né? Eu, com esse número já faço muito barulho. (Renata, $\mathrm{CN}$ )

Para finalizar este tópico, vale ressaltar que enquanto em algumas localidades não se consegue atingir um número mínimo de crianças para participar do Programa (NUNES JUNIOR; AMARAL, 2008), em outras, existem listas de espera, como foi constatado em Pelotas, no ano de 2005 (MENDES et al., 2007). 


\section{Facilitadores}

Cinco das coordenadoras de núcleo entrevistadas acreditam que a alimentação oferecida pelo Programa atrai as crianças.

[Algumas crianças] acabam vindo realmente porque tem o lanche. Fila de lanche, hora do lanche é um caos assim, todo mundo quer, já corre pra fila, quer pegar lanche. (Luciane, $\mathrm{CN}$ )

Outro estudo também demonstra a importância do lanche para a participação de crianças e adolescentes no PST (MENDES et al., 2007). Conforme aponta Athayde (2009, p. 107), em um programa como o PST que se propõe a atender crianças carentes, outras ações, como a oferta de lanche, por exemplo, "acabam ganhando o mesmo grau de importância das atividades principais do programa (esportivas)". Já segundo outra pesquisa que fez uma avaliação do PST no país como um todo, $95 \%$ dos participantes afirmaram que continuariam a frequentar o Programa se o lanche não fosse servido, o que indica que o mesmo não é o principal atrativo do PST (SOUSA et al., 2010).

Algumas coordenadoras elogiaram o fato de terem dois dias livres ${ }^{4}$ por semana para poderem realizar o planejamento de atividades, organizar materiais e fazer contanto com pais, entre outras funções.

O horário de planejamento, isso é [...] excelente [...]. Você vai trabalhar 20 horas em escola, você tem quatro horas pra planejar. Aqui você trabalha 12 e tem 8 pra planejar, você quase tem uma hora de atividade pra uma hora de planejamento quase, né? [...] A gente pode usar pra organizar ficha e tal, arrumar material, fazer qualquer manutenção que tem que fazer aqui. (Luciane, $\mathrm{CN}$ )

Outros facilitadores para a implementação do Programa são o apoio por parte das pessoas responsáveis pelo local onde o mesmo ocorre e a qualidade dos materiais esportivos disponibilizados.

4- $\mathrm{O}$ convênio pesquisado estabeleceu que três dias da semana seriam destinados às atividades com os alunos e dois dias para as atividades de planejamento.

Pensar a Prática, Goiânia, v. 16, n. 4, p. 956-1270, out./dez. 2013 
[Ela] incentiva, sempre que a gente quer fazer um evento ela ajuda. Ela vem e trabalha junto, consegue coisas pela associação [...] [Os materiais] são todos de marca e tal, são bem bons [...] possibilita trabalhar tranquilamente. Em 2005 quando eu era estagiário [...] eu tinha bola que você chutava era capaz de você quebrar um pé se você chutasse muito forte, porque elas eram horríveis. (Luciane, $\mathrm{CN}$ )

A pesquisa de avaliação do Programa de Sousa et al. (2010) também constatou que os materiais esportivos são considerados de boa qualidade. No entanto, conforme descreve a entrevistada acima, bem como algumas pesquisas realizadas antes das reformulações do PST (ATHAYDE, 2009; SILVA; ROCHA, 2007; SOUSA NETO; RODRIGUES, 2007), até 2007 os materiais fornecidos eram de péssima qualidade, pouca durabilidade e, em alguns casos inclusive, "provocavam contusões" nas crianças.

\section{Ora barreira, ora facilitador}

Muitos dos locais onde estão inseridos os núcleos do PST não possuem estrutura física adequada para o desenvolvimento das atividades e nem para atender as 100 crianças que supostamente devem fazer parte do Programa. Os núcleos inseridos em escolas, além de enfrentar o problema de falta de espaço, pois muitas vezes precisam dividi-lo com a Educação Física do ensino regular, enfrentam ainda reclamações devido ao barulho das crianças que acabam atrapalhando o trabalho de outros professores em sala de aula.

O pátio é do lado das salas, as crianças fazem barulho, direção, professoras vêm falar com a gente "manda eles ficarem quietos". [...] [Às vezes] aparece a professora de educação física com as crianças dela lá, e daí eu tenho que tirar todas as minhas crianças da quadra e levar pro pátio, remanejar a aula e tudo mais. (Flávia, $\mathrm{CN}$ )

A falta de infraestrutura das escolas públicas para a implementação do PST é denunciada em outros estudos, como por exemplo, Athayde (2009) e Terra e Mascarenhas (2010). Neste contexto, Terra e Mascarenhas (2010) fazem um questionamento: por que investir um "segun- 
do tempo da educação", enquanto o "primeiro tempo" ainda enfrenta tantas dificuldades (falta de espaços físicos e materiais, falta de formação continuada e professores mal remunerados)?

Assim como algumas de nossas entrevistadas reclamaram, outras elogiaram a infraestrutura disponível para as atividades do PST. O mesmo foi relatado em outras pesquisas sobre o Programa (NUNES JUNIOR; AMARAL, 2008). Já a falta de estrutura adequada para o desenvolvimento do PST também foi relatada nos estudos de Mendes et al. (2007), Silva e Rocha (2007) e Sousa Neto e Rodrigues (2007).

Outra questão correlata à infraestrutura do Programa se relaciona com a disponibilidade, ou não, de locais apropriados para guardar os materiais e lanches e de salas adequadas para o planejamento do trabalho. Existe também a questão da manutenção, ou não, dos espaços destinados às práticas esportivas. Mas, conforme apontou uma das coordenadoras do Programa, a manutenção dos equipamentos da prefeitura e do estado é difícil porque dependem de ações intersetoriais.

Foge da secretaria de esportes, aí tem que ir para uma secretaria do planejamento, aí a secretaria do planejamento tem que passar pela secretaria de obras, aí tem esse efeito em cascata, e a coisa não acontece. (Bárbara, $\mathrm{CP}$ )

A presença de outros programas de contraturno escolar na comunidade ora é vista como um facilitador para a implementação do Programa, ora como barreira. De acordo com a coordenadora do Programa entrevistada, a existência de outros programas no mesmo local do PST só foi percebida após a implementação dos núcleos. Isso ocorreu pela falta diálogo entre as secretarias - de Esporte, de Educação e de Ação Social.

A gente começou a perceber, a detectar só essas falhas no momento em que esses projetos começaram a entrar em choque. Em momento nenhum teve um diálogo entre as secretarias, de como está acontecendo, por que está fazendo isso, por que está fazendo aquilo. (Bárbara, $\mathrm{CP}$ )

A existência de outros programas no mesmo local das atividades do PST se constitui como barreira quando os horários das atividades 
coincidem e/ou quando existe alguma determinação de que as crianças não podem participar de dois programas federais ao mesmo tempo.

A coordenação do núcleo foi muito resistente à implementação do PST. [...] Quando o PST foi entrar no ginásio, é, a coordenação [do município] falou que quem participava do [...] Projeto $[\mathrm{X}]$, não poderia participar do PST [...]. Nós teríamos que dividir entre alunos do PST e Projeto [X] [...]. Então eu cheguei como uma ameaça, porque eu iria tirar, principalmente pelos atrativos do PST [...]. As crianças iriam aderir ao PST e iriam sair do [...] Projeto [X]. Então desde o início da minha estada lá, eu sofri e soube relatos das próprias crianças de que ela chegava e falava: "oh, veja bem, você vai participar do PST, você não vai mais participar do Projeto $[\mathrm{X}]$, você não quer ser atleta? Você não vai poder competir". (Vanessa, $\mathrm{CN}$ )

Em alguns casos a presença de outro programa nos mesmos dias e horários funciona como um facilitador, quando não existe restrição quanto à participação das crianças em ambos os programas e quando é possível fazer uma divisão de espaços.

Até o final do ano tava tendo um outro projeto aqui [...]. Eles estavam fazendo também atividades no mesmo horário que a gente [...]. Então na terça-feira eles faziam atividades só eles, e na segunda, quarta e sexta a gente dividia o espaço [...]. [As crianças] participam dos dois projetos. (Luciane, $\mathrm{CN}$ )

O público alvo dos projetos e programas de esporte e lazer é normalmente o de crianças e adolescentes em situação de risco social. Desta forma, regiões mais carentes tendem a receber uma variedade de propostas que às vezes se sobrepõem e causam, em alguns casos, problemas de adesão e aderência às atividades ofertadas. Este problema provavelmente poderia ser amenizado se houvesse um melhor planejamento por parte das autoridades públicas e outras entidades envolvidas na idealização destas propostas. 


\section{Considerações finais}

As principais barreiras para a implementação do Programa, segundo um dos coordenadores do PST no município, são: incompatibilidade entre os interesses dos gestores do município, os objetivos do Programa e as complexidades envolvidas na implementação do mesmo; carência de pessoal para coordenar o Programa no nível do município, o que sobrecarrega os coordenadores e dificulta o acompanhamento dos núcleos; falta de articulação entre as diferentes secretarias do município para promover ações conjuntas que facilitem a implementação do PST. Para os coordenadores de núcleo, as principais barreiras são: falta de materiais; falta de apoio para o desenvolvimento do trabalho; "engessamento" da proposta do PST; falta de autonomia para tomada de decisões perante os responsáveis pelos locais onde o Programa é sediado; e dificuldade para se atingir o número mínimo de 100 crianças por núcleo exigido pelo ME.

Os principais facilitadores para a implementação do PST, na visão dos coordenadores de núcleo, são: reforço alimentar; carga horária para planejamento; apoio da pessoa responsável pelo local onde o núcleo está sediado; e oferta de materiais esportivos de boa qualidade. Alguns fatores são percebidos ora como barreiras e ora como facilitadores para a implementação do Programa, dependendo da realidade encontrada: estrutura física para o desenvolvimento das atividades $\mathrm{e}$ armazenamento de materiais e lanches e presença de outros programas nas proximidades onde o PST é desenvolvido.

Antes de concluirmos, gostaríamos de ressaltar que projetos de contraturno como o PST são fundamentais no atendimento de crianças e adolescentes. No entanto, ao nosso ver, o ideal seria a oferta de educação integral em tempo integral de forma universal (para todas as crianças) dentro da própria escola, de acordo com um projeto político pedagógico adequado para este fim. Finalmente, gostaríamos também de frisar que esta pesquisa foi realizada em um determinado tempo e espaço do Programa. Considerando que a realidade é dinâmica e que cada região, cidade, bairro e núcleo do Programa possuem suas particularidades, não podemos generalizar os nossos resultados. Mais estudos são necessários para uma melhor compreensão do Programa e para que possamos gerar mais subsídios para o desenvolvimento do PST. 


\title{
BARRIERS AND FACILITATORS FOR THE IMPLEMENTATION OF THE PROGRAM SEGUNDO TEMPO: A CASE STUDY
}

\begin{abstract}
We have investigated the main barriers and facilitators to the implementation of the Program Segundo Tempo (PST). The research was qualitative and the data collected through semi-structured interviews. For the coordinator of the PST in the city, the main barriers relate to the lack of integration between the interests of the parties involved. For the core coordinators, they are related to the lack of autonomy and support to work. The key facilitators are the offering sporting materials, time to plan the activities and the snack offered to children. Some factors are perceived either as barriers or facilitators: physical structure for the activities and to store materials, and the presence of other nearby programs where the PST is developed.
\end{abstract}

Keywords: Public Policies. Sports. Case Studies.

\section{BARRERAS E FACILITADORES PARA LA IMPLEMENTACIÓN DEL PROGRAMA SEGUNDO TIEMPO: UN ESTUDIO DE CASO}

\section{Resumen}

Investigamos las principales barreras y facilitadores para la implementación del Programa Segundo Tiempo (PST). La investigación fue cualitativa y los datos recogidos a través de entrevistas semi-estructuradas. Para el coordinador del PST en la ciudad, las principales barreras se refieren a la falta de integración entre los intereses de las partes involucradas. Para los coordinadores de núcleos, están relacionados con la falta de autonomía y apoyo para trabajar. Los facilitadores son los artículos deportivos ofrecidos, el tiempo para la planificación de las actividades y la alimentación complementaria para los niños. Algunos factores son percibidos como barreras o facilitadores: la estructura física para las actividades y almacenamiento de los materiales y la presencia de otros programas cercanos donde se desarrolla el PST.

Palabras clave: Políticas Públicas. Deportes. Estudios de Casos.

\section{Referências}

ATHAYDE, P. F. A. Programa Segundo Tempo: conceitos, gestão e efeitos. 2009. 183 f. Dissertação (Mestrado em Educação Física)-Faculdade de Educação Física, Universidade de Brasília, Brasília, 2009. Disponível em: <http://repositorio.bce.unb.br/bitstream/10482/4229/1/2009_PedroFernandoAvaloneAthayde.pdf $>$ Acesso em 31 jul. 2012.

ATHAYDE, P. A.; MASCARENHAS, F. Descentralização de políticas sociais: limites para a consolidação de uma gestão democrática do Programa Segundo Tempo. In: CONGRESSO BRASILEIRO DE CI- 
ÊNCIAS DO ESPORTE, 17., 2011, Porto Alegre. Anais... Porto Alegre: CBCE, 2011. p. 1-14. Disponível em: <http://cbce.tempsite.ws/congressos/index.php/XVII_CONBRACE/2011/paper/view/359 1/1793> Acesso em: 31 jul. 2012.

. Políticas sociais esportivas: uma análise da gestão do Programa Segundo Tempo e alguns de seus reflexos no Distrito Federal. In: CONGRESSO BRASILEIRO DE CIÊNCIAS DO ESPORTE, 16., 2009, Salvador. Anais... Salvador: CBCE, 2009. p. 1-14. Disponível em: $<$ http://www.rbceonline.org.br/congressos/index.php/CONBRACE/XVI/paper/view/694/782> Acesso em 31 jul. 2012.

BRASIL. Ministério do Esporte. Texto Básico. In: CONFERÊNCIA NACIONAL DO ESPORTE, 3., Brasília, 2010. Disponível em: $<$ http://www.esporte.gov.br/conferencianacional/arquivos/textoBasico.pdf> Acesso em 02 ago. 2012.

. Ministério do Esporte. Diretrizes do Programa Segundo Tempo 2011. Brasília, 2011a. Disponível em: <http://www.esporte.gov.br/arquivos/snee/segundoTempo/DiretrizesdoProgramaSegundoTempo.pdf $>$ Acesso em: 16 ago. 12.

Secretaria de Comunicação Social da Presidência da República (SECOM). Boletim 1364: Dobra número de crianças e adolescentes atendidos pelo Segundo Tempo. Brasília: [s. n.], $2011 \mathrm{~b}$. Disponível em: <http://www.secom.gov.br/sobre-a-secom/acoes-eprogramas/comunicacao-publica/em-questao/edicoes-anteriores/setembro-2011/boletim-1364-06.09/dobra-numero-de-criancas-e-adolescentes-atendidos-pelo-segundo-tempo > Acesso em: 01 ago. 2012.

GLASER, B. G.; STRAUSS, A. L. The discovery of grounded theory: strategies for qualitative research. Chicago: Aldine, 1967.

LORENZINI, A. R.; SANTOS, A. L. F. Programa Segundo Tempo no agreste de Pernambuco: uma experiência interinstitucional e interdisciplinar. In: CONGRESSO BRASILEIRO DE CIÊNCIAS DO ESPORTE, 16., 2009, Salvador. Anais... Salvador: CBCE, 2009. Disponível em: $\quad<$ http://www.lume.ufrgs.br/bitstream/handle/123456789/96/anais\%20conbrace\%202.pdf?sequence $=3>$ Acesso em: 31 jul. 2012. 
MENDES, V. R. et al. Como os pais percebem a participação dos filhos no Programa Segundo Tempo. In: CONGRESSO BRASILEIRO DE CIÊNCIAS DO ESPORTE, 15., 2007, Recife. Anais... Recife: CBCE, 2007. p. 1-6. Disponível em: <http://www.cbce.org.br/cd/resumos/265.pdf> Acesso em: 31 jul. 2012.

MOREIRA, B. D. et al. Projeto segundo tempo: configurando um modelo. In: CONGRESSO BRASILEIRO DE CIÊNCIAS DO ESPORTE, 15., 2007, Recife. Anais... Recife: CBCE, 2007. Disponível em: <http://www.cbce.org.br/cd/resumos/285.pdf $>$ Acesso em: 31 jul. 2012.

NUNES JUNIOR, P. C.; AMARAL, S. C. F. Esporte e política pública: o caso do Segundo Tempo em Campinas. In: ENCONTRO DA ALESDE, 1., 2008, Curitiba. Anais... Curitiba: ALESDE, 2008. p. 18. Disponível em: <http://www.lume.ufrgs.br/bitstream/handle $/ 123456789 / 37 /$ anais\%20alesde.pdf? sequence $=3 \&$ locale $=$ en $>$ Acesso em 31 jul. 2012.

SILVA, S. M. O.; ROCHA, L. A. O. Programa Segundo Tempo na cidade de Lauro de Freitas - BA: a teoria e a prática. Educacion Física y Deportes, Buenos Aires, v. 12, n. 114, p. 1-1, nov., 2007. Disponível em: $\quad<$ http://www.efdeportes.com/efd114/programa-segundo-tempo.htm > Acesso em 31 jul. 2012.

SOUSA, E. S. et al. Sistema de monitoramento \& avaliação dos programas Esporte e Lazer da Cidade e Segundo Tempo do Ministério do Esporte. Belo Horizonte: O Lutador, 2010. 184p.

SOUSA NETO, L. G.; RODRIGUES, A. M. S. Projeto Segundo Tempo - implantação na unidade escolar Paulo Ferraz em Teresina-PI. In: ENCONTRO DE PESQUISA EM EDUCAÇÃO FÍSICA E ÁREAS AFINS, 2., 2007, Piauí. Anais... Piauí: UFPI, 2007. p. 1-5. Disponível

$<$ http://www.lume.ufrgs.br/bitstream/han-

em:

dle/123456789/32/anais\%20edncontro\%20EFI.pdf?sequence $=3>$ Acesso em: 31 jul. 2012.

TERRA, A. M.; MASCARENHAS, F. O Programa Segundo Tempo e suas implicações para a educação física escolar em Goiânia: um estudo de caso. In: CONGRESSO CENTRO-OESTE DE CIÊNCIAS DO ESPORTE, 4., 2010, Brasília.; CONGRESSO DISTRITAL DE CI- 
ÊNCIAS DO ESPORTE, 1., 2010, Brasília. Anais... Brasília: CBCE, 2010. Disponível em: <http://cbce.tempsite.ws/congressos/index.php/4concoce/4concoce/paper/viewFile/2559/1228> Acesso em: 31 jul. 2012.

Recebido em: 14/09/2012

Revisado em: 22/01/2013

Aprovado em: 25/02/2013

\section{Endereço para correspondência}

desouzdo@post.harvard.edu

Doralice Lange de Souza

Universidade Federal do Paraná, Setor de Ciências Biológicas.

Rua Coração de Maria, 92

Jardim Botânico

80215370 - Curitiba, PR - Brasil 